\title{
Psychological impact of home isolation on children aged 6-14 years during the COVID-19 pandemic in Tabuk, Saudi Arabia 2020
}

\author{
Khalil Abu Jamileh, RCGP, Ibrahim Al Hariri, SBFM, Mohammad R. Ali, MRCGP, Nasrin S. Saiyed, MSc, \\ Ibrahim M. Farouk, MRCGP, Khalid H. Makki, GP, Nehal A. Al Salami, MRCGP, Seham S. Aly, MRCGP, \\ Mustafa Al Toonisi, MBBS, DCH, Menahi Al Subaie, SB-Psych.
}

\begin{abstract}

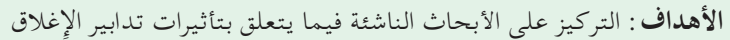

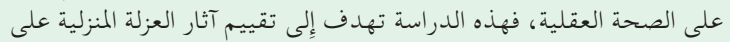

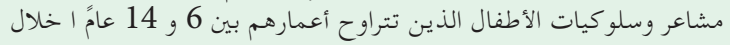
جائحة فيروس كرونا المستجد . مئل

المنهجية : أجريت دراسة مقطعية خلال الفترة من يونيو 2020 2020م إلى أغسطس فئس

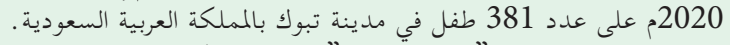

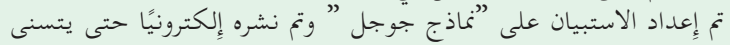

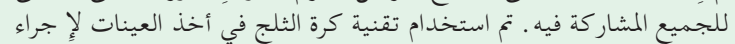

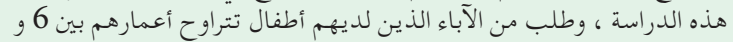

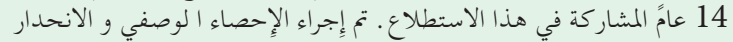

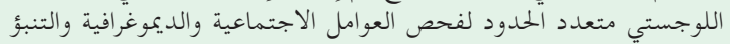

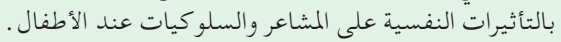

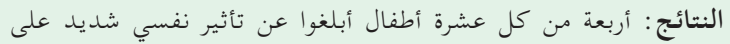

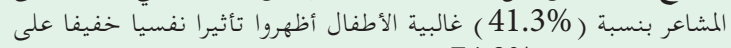

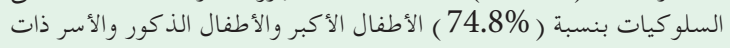

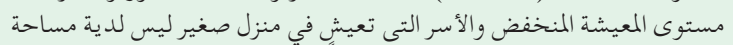

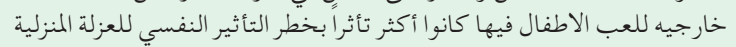

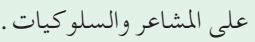

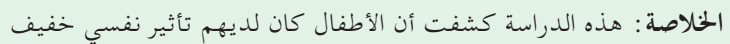

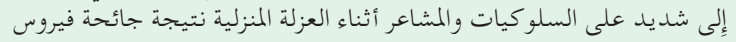

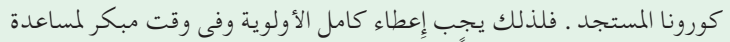

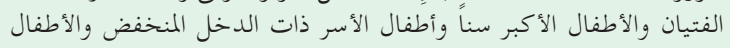

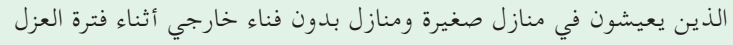

Objectives: To evaluate the impact of home isolation on feelings and behaviors of children aged 6-14 years during COVID-19 pandemic in Tabuk, Saudi Arabia.

Methods: A cross-sectional study was conducted between June and August 2020 in Tabuk, Saudi Arabia. A snowball sampling was applied, parents with children aged 6-14 years participated in this survey $(\mathrm{N}=361)$. questionnaires were distributed electronically.
Results: Four out of ten children reported severe psychological impact on feelings (41.3\%), while a majority of the children demonstrated mild psychological impact on behavior (74.8\%). Age was associated with risk of psychological impact on behavior (OR: 7.24, 95\% CI: 1.35-16.18). Being male was associated with risk of psychological impact on feelings (OR: 2.38, 95\% CI: 0.67-6.43), and behavior (OR: 3.50, 95\% CI: 0.42-6.00). Living in a small house or without an outside play area was associated with risk of psychological impact on feelings and behaviors.

Conclusion: This study revealed that children experienced mild-to-severe psychological impact on behaviors and feelings during home isolation during COVID-19 pandemic. Priority should be given to boys, older age, children of low-income families, living in small houses and those without outside play areas.

Keywords: COVID-19, psychology, children, home isolation, social distancing, quarantine

Saudi Med J 2021; Vol. 42 (10): $1095-1102$ doi: 10.15537/smj.2021.42.10.20210091

From the Family Medicine Department (Abu Jamileh, Al Hariri, Ali, Farouk, Makki, Al Salami, Aly), from the Research Department (Saiyed), from the Pediatric Department (Al Toonisi), and from the Psychiatric Department (Al Subaie), King Salman Armed Forces Hospital, Tabuk, Kingdom of Saudi Arabia.

Received 11th February 2021. Accepted 24th August 2021

Address correspondence and reprint request to: Dr. Mohammad R. Ali, Family Medicine Department, King Salman Armed Forces Hospital, Tabuk, Kingdom of Saudi Arabia. E-mail: aboammarradwan@gmail.com ORCID ID: http://orcid.org/0000-0002-0120-7869 
$\mathrm{T}$ he coronavirus disease (COVID-19) has no known cure at present, and has affected nations across the globe, spreading at an exponential rate and imposing a major health threat to the population. ${ }^{1}$ Further, the COVID-19 pandemic has created a significant challenge for health authorities. ${ }^{2}$ Consequently, different preventive measures have been implemented by governments, such as physical and social distancing, more rigorous hygiene practices, wearing protective facial coverings and lockdowns in affected countries, ${ }^{3}$ which have resulted in dramatic changes to peoples' daily lives. ${ }^{4}$ Operational definition of feeling is the basic perception of events experienced through sense organs with subsequent generation of emotional reaction, while operational definition of behavior is the activities generated in response to external or internal stimuli including observable activities and non con-conscious processes. As a result of school closures and strict restrictions regarding going outside, children have been one of the most disadvantaged population groups during the lockdown period. ${ }^{5,6}$ While children appear to be less prone to COVID-19 than adults, initial reports from different affected countries suggested that children and adolescents have been psychologically affected, manifesting a behavioral problems. ${ }^{7}$ Another critical issue concerns emotional problems. Previous studies have shown that a long period of home isolation can have a major, negative psychological effect on adults triggering negative moods such as depression, anxiety and stress. ${ }^{8-11}$ While studies have been conducted throughout the world on the psychological issues resulting from the COVID-19 pandemic, these have been limited to adults only. ${ }^{12-14}$ It is perhaps inevitable that an increase in COVID-19 cases would lead to emotional and behavioral changes among children and have an adverse effect on their physical and mental health development. ${ }^{15-17}$ Therefore, the purpose of this study was to investigate the potential psychological impact of home isolation on feelings and behaviors among children aged 6-14 years in Tabuk, Saudi Arabia during the COVID-19 pandemic.

Methods. A cross-sectional design was applied consisting of an online questionnaire survey. Due to the restriction resulting from the COVID-19 pandemic, it was not feasible to carry out this survey in person.

Disclosure. Authors have no conflict of interests, and the work was not supported or funded by any drug company.
The study was conducted in Tabuk city, the largest city in the north western region of Saudi Arabia that lies close to the Jordan-Saudi Arabia border, with a population of approximately 1 million. Parents living in Tabuk city who were recruited to take part were instructed to ask the pre-determined questions about the psychological impact of home isolation to their children. The survey consisted of entirely closed questions. Feedback from the parents was gathered during the active survey period (June-August 2020). The sample size was calculated using Epi Info version 7 (Centers for Disease Control and Prevention [CDC], Atlanta, Georgia, USA). The calculated sample size was $\mathrm{N}=384$ based on the assumption of an anticipated $50 \%$ frequency response and 5\% margin of error, confidence interval of $95 \%$ and a design effect of 1.0. A snowball non-probability sampling technique was used to recruit the participants.

The inclusion criteria were as follows: parents (of children aged 6-14 years) who were of any gender, any nationality, living in Tabuk, able to read and write, able to access an Internet facility at home or by mobile. The exclusion criteria were as follows: adults who were not parents, adults who were parents, with children aged less than 6 years or more than 14 years, not able to read write, outside the study period, not living in Tabuk, not willing to participate in the study, having children with any disability/illness (physical or mental).

The questionnaire was developed by a panel of experts following a comprehensive literature review. The questions used to measure psychological impact evaluate 2 internalizing conditions: feelings and behaviors. These emotional and behavioral conditions were selected because of their critical importance as demonstrated in the literature and were evaluated using a set of categorical questions that had 3 possible responses ('Yes', 'No', and 'I Don't Know'). The questionnaire was first prepared in English and then semantic translation was conducted using Arabic by bilingual language experts. The survey consisted of 3 parts. Demographics questions were used to gather information on the child's age and gender. Other risk factors, including parents' educational level, employment status, employment sector, occupation, and family income were recorded together with details about the number of family members, number of rooms in the house and play area outside the house. The section concerning psychological impact of home isolation consisted of 15 questions on feelings and 8 questions on behaviors. The survey used age-appropriate language suited to children aged 6-14 years. The questionnaire was prepared on Google Forms and was distributed online. The survey link was sent 
through social media (such as WhatsApp, Snapchat, Facebook and Twitter). Telephone calls were also made to invite the participants. After clicking on the survey link, the study participants were directed to an introductory page, which included the title and purpose of the study. Consent for participation and confidentiality of the data were explained, and after reading this, the participants were asked to click on 'Start the survey'. On completion of the questionnaire, participants were then directed to click the 'Submit' option.

Each question was recorded with a response, which was recoded as follows: $1=$ 'Yes', $-1=$ 'No' and $0=$ 'I don't know'. The psychological impact of home isolation on children was measured using the cumulative score of questions mentioned in the respective section of the questionnaire. The total score for the feelings subscale score was categorized as normal (0-6), mild (7-9), moderate (10-12) and severe (13-15) psychological impact on feelings. The total score for the behaviours subscale score was subdivided into normal (0-2), mild (3-4), moderate (5-6) and severe (7-8) psychological impact on behaviors. Family income was divided into 2 categories: low-income family $(<10,000$ SAR), and high-income family ( $>10,000$ SAR). Family size was divided into two categories: small family $(<5$ members), and big family ( $>5$ members). House size was divided into two categories: small house ( $<5$ rooms), and big house ( $>5$ rooms).

While developing the questionnaire, appropriate scales were defined. Two different researchers crosschecked the data to ensure good quality. Survey data were collected in Google Forms and analyzed using SPSS (version 26.0). The feelings and behaviors of the children were considered the dependent variables, while sociodemographic characteristics (age, gender, monthly family income, family size, house size and play area outside the house) were the independent variables. The internal accuracy of the questionnaire was checked using the Cronbach alpha test, from which it was determined that the reliability of the questionnaire was acceptable (0.861 reliability coefficient). Descriptive statistics were calculated, which included frequency, percentage, mean and standard deviation. Multinomial logistic regression analysis was performed to investigate the effect of home isolation on feelings and behaviors. A p-value of $<0.05$ was considered statistically significant.

The study included bold-frame instructions indicating that the research would be kept confidential and participants were anonymous as they did not include their names on the questionnaire. Voluntary submission of the completed online questionnaire was considered full consent to participate. Ethical approval of the study was obtained from the Local Research and Ethics Committee at KSAFH (Ethical Approval Number: KSAFH-REC-2020-330).

Results. Formally invited participants were 384 and those who respond were 361 thereby response rate were 94\%. Tables are shown at the end of the text and for each table brief demonstration are set out below: Table 1 presents the sociodemographic results for the participants. From the study sample $(\mathrm{N}=361)$, approximately $45.4 \%$ children were aged between 6 and 8 years, while the mean age was 9.06 years $(\mathrm{SD}=2.43$ years). Half the children were male $(51.2 \%)$. A majority of the children's parents were college/ university graduates (70.4\%), had full-time work $(57.6 \%)$ and were employed in the government sector (84.8\%). Approximately $40 \%$ of the children's parents had a monthly income more than 10,000 SAR (39.6\%). Seven out of 10 children's parents had 5 or more family members in the house (72.3\%). Most of the children's parents had big house with 5 or more rooms $(45.7 \%)$ and had a play area outside the house (63.4\%) (Table 1).

Table 2 presents the responses regarding the psychological impact of home isolation on children's feelings. The parents asked their children the questions identified in Table 2. When asked about COVID-19, approximately $78.6 \%$ of the children thought that COVID-19 is a serious disease. A majority of the children were worried that they might have caught COVID-19 (73.9\%). Three quarters of the children agreed that they were suffering because they could not leave their house and had to stay at home (75.1\%). Most of the children were unhappy because they did not see and meet their friends (77.8\%). Approximately $73 \%$ of the children felt either lonely or bored. Six out of 10 children felt isolated from others during the home isolation 10 periods (64.8\%).

Table 3 illustrates the psychological impact of home isolation on children's behaviors. The parents asked the following questions of their children. Out of 361 children, a large majority knew about the COVID-19 virus (92.5\%). When asked about following the recommendations to protect from the virus, most of the children agreed that they had followed them (96.4\%). Three quarters of the children were afraid of germs and did not want to touch things (77.6\%). A majority $(67.3 \%)$ of the children agreed that they were punished by their parents because of not obeying their orders during the home isolation period.

Table 4 reports the varying degrees of psychological impact of home isolation on the feelings and behaviors of children during the pandemic. Among the 361 
Table 1 - Sociodemographic of the study participants ( $N=361)$.

\begin{tabular}{|c|c|c|}
\hline Sociodemographic & $\mathbf{n}$ & $(\%)$ \\
\hline \multicolumn{3}{|l|}{ Age of the child (years) } \\
\hline $6-8$ & 164 & $(45.4)$ \\
\hline $9-11$ & 132 & $(36.6)$ \\
\hline $12-14$ & 65 & $(18.0)$ \\
\hline Mean \pm SD (years) & \multicolumn{2}{|c|}{$9.06 \pm 2.43$} \\
\hline \multicolumn{3}{|l|}{ Gender of the child } \\
\hline Male & 185 & $(51.2)$ \\
\hline Female & 176 & $(48.8)$ \\
\hline \multicolumn{3}{|c|}{ Parent's highest education } \\
\hline No schooling & 5 & $(1.4)$ \\
\hline Primary school & 25 & $(6.9)$ \\
\hline Intermediate school & 77 & $(21.3)$ \\
\hline College/University & 254 & $(70.4)$ \\
\hline \multicolumn{3}{|c|}{ Parent's employment status } \\
\hline Unemployed & 26 & $(7.2)$ \\
\hline Full-time work & 208 & $(57.6)$ \\
\hline Part-time work & 100 & $(27.7)$ \\
\hline Retired & 27 & $(7.5)$ \\
\hline \multicolumn{3}{|c|}{ Parent's employment sector } \\
\hline Government & 306 & $(84.8)$ \\
\hline Non-government & 55 & $(15.2)$ \\
\hline \multicolumn{3}{|c|}{ One of parents works as medical staff } \\
\hline Yes & 107 & $(29.6)$ \\
\hline No & 254 & $(70.4)$ \\
\hline \multicolumn{3}{|l|}{ Parent's occupation } \\
\hline Doctor & 54 & $(15.0)$ \\
\hline Nursing staff & 25 & $(6.9)$ \\
\hline Other medical staff & 21 & $(5.8)$ \\
\hline Technical staff & 7 & $(1.9)$ \\
\hline Non-medical staff & 254 & $(70.4)$ \\
\hline \multicolumn{3}{|c|}{ Monthly family income (SAR) } \\
\hline$<3,000$ & 19 & $(5.3)$ \\
\hline $3,000-5,000$ & 46 & $(12.7)$ \\
\hline $6,000-10,000$ & 153 & $(42.4)$ \\
\hline $11,000-20,000$ & 119 & $(33.0)$ \\
\hline$>20,000$ & 24 & $(6.6)$ \\
\hline \multicolumn{3}{|c|}{ Total no. of family members } \\
\hline$<3$ members & 8 & $(2.2)$ \\
\hline 3 members & 22 & $(6.1)$ \\
\hline 4 members & 70 & $(19.4)$ \\
\hline 5 or more members & 261 & $(72.3)$ \\
\hline \multicolumn{3}{|l|}{ No. of rooms in the house } \\
\hline$<3$ rooms & 12 & $(3.3)$ \\
\hline 3 rooms & 69 & $(19.1)$ \\
\hline 4 rooms & 115 & $(31.9)$ \\
\hline 5 or more & 165 & $(45.7)$ \\
\hline \multicolumn{3}{|c|}{ Play area outside the house } \\
\hline Yes & 229 & $(63.4)$ \\
\hline No & 132 & (36.6) \\
\hline
\end{tabular}

children, $1 \%$ had normal feelings, whereas the proportions of children has mild, moderate, and severe psychological impact of home isolation. Approximately $17 \%$ had normal behaviors, while the percentages of children with mild, moderate, and severe psychological impact of home isolation on behaviors were summarized in Table 4.

Table 5 presents the output of multinomial logistic regression modelling that differentiates the varying degree of psychological impact on children during home isolation. The analysis indicates that the fitted models for feelings and behaviors were good (behaviors: $x^{2}=653.88, p<0.0001$, co-efficient of determination Nagelkerke $R^{2}=0.752$; feelings: $x^{2}=732.34, p<0.001$, coefficient of determination Nagelkerke $\mathrm{R}^{2}=0.872$ ). These results suggest that the above models satisfactorily differentiate between the mild, moderate and severe psychological impact of home isolation on feelings and behaviors from a normal status.

The statistical results indicate that older age was significantly associated with children being at risk of psychosocial impact on feelings (OR: 3.77, 95\% CI: 0.93-7.86) and behaviors (OR: 7.24, 95\% CI: 1.3516.18). Being male was significantly associated with being at risk of psychosocial impact on both feelings and behaviors, as was monthly family income (feelings: [OR: 2.72, 95\% CI: 0.96-5.98) and behaviors: (OR: 2.87, 95\% CI: 0.22-8.59). Those children living in small houses were more likely to be at risk of psychosocial impact on both feelings and behavior's than children living in big houses. Play area outside of the house was significantly associated with being at risk of psychosocial impact on feelings (OR: 2.08, 95\% CI: 0.78-5.53) and behaviors (OR: 2.29, 95\% CI: 0.19-8.20) as shown in Table 5.

Discussion. While the global implementation of lockdown has reduced the spread of the COVID-19 virus, it has affected the emotional and psychological state of the population..$^{18}$ Older age was clear indicator of psychological impact on both feelings and behaviors across the sample. Gender was also an important risk factor, as boys were more likely than girls to be at risk of psychological impact on behaviors. This finding also echoes results from studies conducted in other countries. ${ }^{19,20}$

This result is in accordance with other studies in which the relation between age and levels of stress throughout isolation have been analyzed. ${ }^{21,22}$ Various research studies have been conducted around the world that demonstrate the state of people's psychological wellbeing during lockdown; however, those studies 
Table 2 - Psychological impact of home isolation on the feelings of the children (N=361).

\begin{tabular}{|c|c|c|c|c|}
\hline Questions & Yes & No & Don't know & Total \\
\hline 1. Do you think that COVID-19 is a very serious disease? & $284(78.6)$ & $67(18.6)$ & $10(2.8)$ & $361(100)$ \\
\hline 2. Are you worried that you may catch COVID-19 virus? & $267(73.9)$ & $79(21.9)$ & $15(4.2)$ & $361(100)$ \\
\hline 3. Are you worried that your friends and family may catch COVID-19 virus? & $320(88.6)$ & $30(8.3)$ & $11(3.0)$ & $361(100)$ \\
\hline 4. Are you afraid to leave the house right now? & $208(57.6)$ & $145(40.2)$ & $8(2.2)$ & $361(100)$ \\
\hline 5. Are you worried you might transmit the infection to someone else? & $262(72.6)$ & $92(25.5)$ & $7(1.9)$ & $361(100)$ \\
\hline $\begin{array}{l}\text { 6. Are you worried you will not have enough food and other essential items during the } \\
\text { pandemic? }\end{array}$ & $95(26.3)$ & $260(72.0)$ & $6(1.7)$ & $361(100)$ \\
\hline 7. Are you sharing your worries and emotions with your family members? & $279(77.2)$ & $67(18.6)$ & $15(4.2)$ & $361(100)$ \\
\hline 8. Are you suffering from not leaving your house and staying at home? & $271(75.1)$ & $81(22.4)$ & $9(2.5)$ & $361(100)$ \\
\hline 9. Are you unhappy because of not seeing and meeting your friends? & $281(77.8)$ & $65(18.0)$ & $15(4.2)$ & $361(100)$ \\
\hline 10. Are you nervous because of your parents' worries? & $108(29.9)$ & $241(66.8)$ & $12(3.3)$ & $361(100)$ \\
\hline 11. Do you feel ignored or neglected? & $140(38.8)$ & $213(59.0)$ & $8(2.2)$ & $361(100)$ \\
\hline 12. Do you feel lonely or bored? & $263(72.9)$ & $82(22.7)$ & $16(4.4)$ & $361(100)$ \\
\hline 13. Do you feel isolated from others? & $234(64.8)$ & $114(31.6)$ & $13(3.6)$ & $361(100)$ \\
\hline 14. Do you feel home isolation is good? & $172(47.6)$ & $175(48.5)$ & $14(3.9)$ & $361(100)$ \\
\hline 15. Do you feel normal during the COVID-19 pandemic? & $114(31.6)$ & $241(66.7)$ & $6(1.7)$ & $361(100)$ \\
\hline
\end{tabular}

Values are presented as number and percentage $(\%)$

Table 3 - Psychological impact of home isolation about behaviors of the children ( $N=361)$

\begin{tabular}{|c|c|c|c|c|}
\hline Behaviors & Yes & No & Don't know & Total \\
\hline 1. Are you following the recommendations to protect yourself from COVID-19? & $348(96.4)$ & $4(1.1)$ & $9(2.5)$ & $361(100)$ \\
\hline 2. Do you sleep well? & $324(89.7)$ & $31(8.6)$ & $6(1.7)$ & $361(100)$ \\
\hline 3. Do you eat well? & $323(89.5)$ & $30(8.3)$ & $8(2.2)$ & $361(100)$ \\
\hline 4. Are you afraid of germs and not want to touch things? & $280(77.6)$ & $64(17.7)$ & $17(4.7)$ & $361(100)$ \\
\hline 5. Are you punished by your parents because of not obeying their orders? & $243(67.3)$ & $105(29.1)$ & $13(3.6)$ & $361(100)$ \\
\hline 6. Do you play games with your parents? & $282(78.1)$ & $72(19.9)$ & $7(1.9)$ & $361(100)$ \\
\hline
\end{tabular}

Values are presented as number and percentage $(\%)$

Table 4 - Comparison of varying degrees of psychological impact of home isolation on the feelings and behaviors of children during the pandemic $(\mathrm{N}=361)$.

\begin{tabular}{lcc}
\hline Categories & $\begin{array}{c}\text { Feelings } \\
\mathbf{n}(\%)\end{array}$ & $\begin{array}{c}\text { Behaviors } \\
\mathbf{n}(\%)\end{array}$ \\
\hline Normal & $3(0.8)$ & $61(16.9)$ \\
Mild & $38(10.5)$ & $270(74.8)$ \\
Moderate & $171(47.4)$ & $28(7.8)$ \\
Severe & $149(41.3)$ & $2(0.6)$ \\
\hline
\end{tabular}

were limited to adult populations. ${ }^{23,24}$ There are few available studies to date that assess the psychosocial effects of home isolation on children during COVID-19 pandemic. $^{7,25}$ In this cross-sectional study, a number of risk factors were presented to analyzed the psychological impact of home isolation on feelings and behaviors among children aged 6-14 years during the COVID-19 pandemic, from which it was determined that older age, being male, belonged to a low-income family group, 
Table 5 - Multinomial logistic regression model differentiating the mild, moderate and severe psychological impact of home isolation on feelings and behaviors.

\begin{tabular}{|c|c|c|c|c|c|c|}
\hline \multirow[t]{2}{*}{ Variables } & \multicolumn{3}{|c|}{ Feelings } & \multicolumn{3}{|c|}{ Behaviors } \\
\hline & $\begin{array}{c}\text { Mild } \\
\text { OR }(95 \% \mathrm{CI})\end{array}$ & $\begin{array}{c}\text { Moderate } \\
\text { OR }(95 \% \mathrm{CI})\end{array}$ & $\begin{array}{c}\text { Severe } \\
\text { OR }(95 \% \mathrm{CI})\end{array}$ & $\begin{array}{c}\text { Mild } \\
\text { OR }(95 \% \mathrm{CI})\end{array}$ & $\begin{array}{c}\text { Moderate } \\
\text { OR }(95 \% \text { CI })\end{array}$ & $\begin{array}{c}\text { Severe } \\
\text { OR }(95 \% \mathrm{CI})\end{array}$ \\
\hline \multicolumn{7}{|l|}{ Age (years) } \\
\hline $6-8$ & Reference & & & & & \\
\hline $9-11$ & $1.85(0.43,3.65) \dagger$ & $1.30(0.43,3.92)^{*}$ & $0.96(0.46,1.74)$ & $1.58(0.10,6.12)^{*}$ & $2.43(0.11,7.85) \dagger$ & $6.41(2.34,18.95) \dagger$ \\
\hline $12-14$ & $1.48(0.23,3.03) \dagger$ & $1.99(0.269,3.37)^{*}$ & $3.77(0.93,7.86)^{*}$ & $2.04(1.33,7.29)^{*}$ & $7.24(1.35,16.18) \dagger$ & $4.10(1.29,10.16)^{*}$ \\
\hline \multicolumn{7}{|l|}{ Gender } \\
\hline Female & Reference & & & & & \\
\hline Male & $1.69(0.67,3.11)^{*}$ & $1.77(0.68,4.60)$ & $2.38(0.67,6.43)^{*}$ & $1.48(0.10,4.12)^{*}$ & $2.54(0.11,7.85)^{*}$ & $3.50(0.42,6.00)^{*}$ \\
\hline \multicolumn{7}{|c|}{ High income family } \\
\hline Yes & Reference & & & & & \\
\hline No & $2.72(0.96,5.98) \dagger$ & $0.57(0.22,1.47)$ & $1.87(0.42,2.82)^{*}$ & $1.67(0.37,6.14)^{*}$ & $2.87(0.22,8.59)^{*}$ & $1.76(1.14,8.52)^{*}$ \\
\hline \multicolumn{7}{|l|}{ Big Family } \\
\hline Yes & Reference & & & & & \\
\hline No & $0.85(0.47,1.55)$ & $0.73(0.22,2.42)$ & $0.27(0.04,1.62)$ & $1.75(0.50,4.08)$ & $1.37(0.10,3.45)$ & $1.58(0.12,5.19)$ \\
\hline \multicolumn{7}{|l|}{ Big House } \\
\hline Yes & Reference & & & & & \\
\hline No & $1.11(0.57,2.18)^{*}$ & $1.83(0.67,5.01)^{*}$ & $2.24(0.50,6.64)^{*}$ & $3.91(1.78,9.60)^{*}$ & $6.60(4.11,10.59) \dagger$ & $5.90(1.48,11.32)^{*}$ \\
\hline \multicolumn{7}{|c|}{ Play area outside the house } \\
\hline Yes & Reference & & & & & \\
\hline No & $1.24(0.66,2.31)^{*}$ & $2.08(0.78,5.53)^{*}$ & $0.98(0.43,1.78)$ & $1.26(0.09,4.54)^{*}$ & $1.36(0.11,5.18)^{*}$ & $2.29(0.19,8.20)^{*}$ \\
\hline & & lue $<0.05,{ }^{\dagger} p$-valu & $=0.01$, OR: odds ra & CI: confidence in & & \\
\hline
\end{tabular}

living in small house and without an outside play area were more likely to impact feelings and behaviors. These results merit further discussion.

This research determined that severe quarantine restrictions affect the feelings and behaviors of the children and is in line with the other studies conducted in both developed and developing countries. ${ }^{26,27}$ The present study revealed that during the COVID-19 pandemic, a significant proportion of children reported stress and fear of being infected with the COVID-19 virus, similar to the findings in other studies. ${ }^{28}$ This study demonstrated that children knew the facts relevant to COVID-19 and followed the recommendations for protection. Similar results were noted among children in developed countries. ${ }^{29,30}$ Moreover, it was observed that 7 out of 10 children claimed that they were becoming bored and suffering from not leaving their houses, and were unhappy because they could not meet with their friends. Consistent with other studies, it was found that approximately three-fifths of children felt isolated from others and thought home isolation was not good. ${ }^{31,32}$ Low household income was another indicator of psychological impact among the studied sample, which is congruent with other studies, suggesting that the economic impact of the lockdown presents an important trigger for mental distress among children. ${ }^{33}$

Other studies have shown that the lockdown caused by COVID-19 has heavily influenced life by completely changing our routines and isolating us from our loved ones. ${ }^{34,35}$ Conversely, the lockdown has allowed more room for people to find time with their loved ones at home. This result was in accordance with those of other regional and international studies. ${ }^{36,37}$ The results from the current study identified that children living in small houses were more vulnerable to high psychological effect during a pandemic. Finally, it had also been shown that houses with no outdoor play areas could cause major psychological effects on feelings and behaviors of the children. This result supports the finding of the other studies. ${ }^{28,38}$

Study limitations. The strength of this study is that it was conducted during the critical time of lockdown. Despite efforts to circulate the survey on all possible social 
media channels, greater participation was expected. Thus, the response rate for the survey was limited. Most of participants were children aged 6-8 years, and it was therefore to answer questions on their own as their parents were required to ask them to answer the survey questions. However, considering the situation, this was the possible best practical methodology to reach to the children to understand the nature of the psychological impact.

In conclusion, the study demonstrated that home isolation affects the feelings and behaviors of male children more than female children. Children aged 12-14 years and belonging to low-income families were more vulnerable to high psychological impact. House size and having a play area outside the house had a major effect on psychological impact on feelings and behaviors. Accordingly, health authorities should focus on post-pandemic strategies to address these emerging issues.

Acknowledgment. We would like to thank all the parents and children who participated in this research. We gratefully acknowledge King Salam Armed Forces Hospital, Tabuk, Kingdom of Saudi Arabi for creating an opportunity to carry out this study. Lastly, we would like to thank Scribendi (www.scribendi.com) for English language editing.

\section{References}

1. Khan I, Haleem A, Javaid M. Analysing COVID-19 pandemic through cases, deaths, and recoveries. J Oral Biol Craniofac Res 2020; 10: 450-469.

2. Armocida B, Formenti B, Ussai S, Palestra F, Missoni E. The Italian health system and the COVID-19 challenge. Lancet Public Health 2020; 5: e253.58

3. Meo SA. COVID-19 pandemic: saudi Arabia's role at national and international levels. J Diabetes Sci Technol 2020; 14: 758-759.

4. Donthu N, Gustafsson A. Effects of COVID-19 on business and research. J Bus Res 2020; 117: 284.

5. Leeb RT, Price S, Sliwa S, Kimball A, Szucs L, Caruso E, Godfred-Cato S, Lozier M. COVID-19 trends among schoolaged children-United States, March 1-September 19, 2020. MMWR Morb Mortal Wkly Rep 2020; 69: 1410.

6. Lee J. Mental health effects of school closures during COVID-19. Lancet Child Adolesc Health 2020; 4: 421.

7. Jiao WY, Wang LN, Liu J, Fang SF, Jiao FY, Pettoello-Mantovani $\mathrm{M}$, et al. Behavioral and emotional disorders in children during the COVID-19 epidemic. J Pediatr 2020; 221: 264.

8. Lebrasseur A, Fortin-Bédard N, Lettre J, Raymond E, Bussières EL, Lapierre N, Faieta J, Vincent C, Duchesne L, Ouellet MC, Gagnon E. Impact of the COVID-19 pandemic on older adults: rapid review. JMIR Aging 2021; 4: e26474.

9. Salari N, Hosseinian-Far A, Jalali R, Vaisi-Raygani A, Rasoulpoor S, Mohammadi M, et al. Prevalence of stress, anxiety, depression among the general population during the COVID-19 pandemic: a systematic review and meta-analysis. Global Health 2020; 16: 1-1.
10. Rehman U, Shahnawaz MG, Khan NH, Kharshiing KD, Khursheed M, Gupta K, et al. Depression, anxiety and stress among Indians in times of Covid-19 lockdown. Community Ment Health J 2021; 57: 42-48.

11. Wilson W, Raj JP, Rao S, Ghiya M, Nedungalaparambil NM, Mundra $\mathrm{H}$, et al. Prevalence and predictors of stress, anxiety, and depression among healthcare workers managing COVID-19 pandemic in India: a nationwide observational study. Indian J Psychol Med 2020; 42: 353-358.

12. Asselmann E, Borghans L, Montizaan R, Seegers P. The role of personality in the thoughts, feelings, and behaviors of students in Germany during the first weeks of the COVID-19 pandemic. PLoS One 2020; 15: e0242904.

13. Grossman ES, Hoffman YS, Palgi Y, Shrira A. COVID-19 related loneliness and sleep problems in older adults: worries and resilience as potential moderators. Pers Individ Dif 2021; 168: 110371.

14. Lee CM, Cadigan JM, Rhew IC. Increases in loneliness among young adults during the COVID-19 pandemic and association with increases in mental health problems. J Adolesc Health 2020; 67: 714-717.

15. Duan L, Shao X, Wang Y, Huang Y, Miao J, Yang X, Zhu G. An investigation of mental health status of children and adolescents in china during the outbreak of COVID-19. J Affect Disord 2020; 275: 112-118.

16. Liu JJ, Bao Y, Huang X, Shi J, Lu L. Mental health considerations for children quarantined because of COVID-19. The Lancet Child \& Adolescent Health 2020; 4: 347-349.

17. Singh S, Roy MD, Sinha CP, Parveen CP, Sharma CP, Joshi CP. Impact of COVID-19 and lockdown on mental health of children and adolescents: A narrative review with recommendations. Psychiatry Res 2020; 24: 113429.

18. Wang C, Pan R, Wan X, Tan Y, Xu L, Ho CS, Ho RC. Immediate psychological responses and associated factors during the initial stage of the 2019 coronavirus disease (COVID-19) epidemic among the general population in China. Int $J$ Environ Res Public Health 2020; 17: 1729.

19. Langenkamp A, Cano T, Czymara CS. My home is my castle? The role of living arrangements on experiencing the COVID-19 pandemic in Germany. ifo Working Papers 2020; 329: 1-61.

20. Etheridge B, Spantig L. The gender gap in mental well-being during the Covid-19 outbreak: Evidence from the UK. ISER Working Paper Series; 2020.

21. Klaiber P, Wen JH, DeLongis A, Sin NL. The ups and downs of daily life during COVID-19: Age differences in affect, stress, and positive events. J Gerontol B Psychol Sci Soc Sci 2021; 76: e30-e37.

22. Horesh D, Brown AD. Traumatic stress in the age of COVID-19: A call to close critical gaps and adapt to new realities. Psychol Trauma 2020; 12: 331.

23. Liu CH, Zhang E, Wong GT, Hyun S. Factors associated with depression, anxiety, and PTSD symptomatology during the COVID-19 pandemic: Clinical implications for US young adult mental health. Psychiatry Res 2020; 290: 113172.

24. Meyer J, McDowell C, Lansing J, Brower C, Smith L, Tully $\mathrm{M}$, et al. Changes in physical activity and sedentary behavior in response to COVID-19 and their associations with mental health in 3052 US adults. Int J Environ Res Public Health 2020; 17: (18). 
25. Imran N, Aamer I, Sharif MI, Bodla ZH, Naveed S. Psychological burden of quarantine in children and adolescents: A rapid systematic review and proposed solutions. Pak J Med Sci 2020; 36: 1106.

26. de Miranda DM, da Silva Athanasio B, de Sena Oliveira AC, Silva AC. How is COVID-19 pandemic impacting mental health of children and adolescents? Int J Disaster Risk Reduct 2020; 10: 101845.

27. Saurabh K, Ranjan S. Compliance and psychological impact of quarantine in children and adolescents due to Covid-19 pandemic. Indian J Pediatr 2020; 87: 532-536.

28. Iqbal SA, Tayyab N. COVID-19 and children: The mental and physical reverberations of the pandemic. Child Care Health Dev 2021; 47: 136-139.

29. Xue Q, Xie X, Liu Q, Zhou Y, Zhu K, Wu H, Wet al. Knowledge, attitudes, and practices towards COVID-19 among primary school students in Hubei Province, China. Child Youth Serv Rev 2021; 120: 105735 .

30. Idoiaga N, Berasategi N, Eiguren A, Picaza M. Exploring children's social and emotional representations of the Covid- 19 pandemic. Front Psychol 2020; 11: 1952.

31. Arora, R. and S.P. Singh, Lockdown Boredom in COVID-19 Pandemic: As a Cause of Pediatric Foreign Bodies. Indian J Otolaryngol Head Neck Surg 2020; 22: 1-2.
32. Caffo EF, Scandroglio, and L. Asta, Debate: COVID-19 and psychological well-being of children and 25 adolescents in Italy. Child Adolesc Ment Health 2020; 25: 167-168.

33. Gassman-Pines, A., E.O. Ananat, and J. Fitz-Henley, COVID-19 and parent-child psychological well-being. Pediatrics 2020; 146: e2020007294.

34. Ramkissoon H. COVID-19 Place confinement, pro-social, pro-environmental behaviors, and residents' wellbeing: A new conceptual framework. Front Psychol 2020; 11: 2248.

35. Górnicka M, Drywień ME, Zielinska MA, Hamułka J. Dietary and lifestyle changes during COVID-19 and the subsequent lockdowns among polish adults: A cross-sectional online survey PLifeCOVID-19 Study. Nutrients 2020; 12: 2324.

36. Russell BS, Hutchison M, Tambling R, Tomkunas AJ, Horton AL. Initial challenges of caregiving during COVID-19: caregiver burden, mental health, and the parent-child relationship. Child Psychiatry Hum Dev 2020; 51: 671-682.

37. Zhou X. Managing psychological distress in children and adolescents following the COVID-19 epidemic: A cooperative approach. Psychol Trauma 2020; 12 (S1): S76-S78.

38. Mitra R, Moore SA, Gillespie M, Faulkner G, Vanderloo LM, Chulak-Bozzer $\mathrm{T}$, et al. Healthy movement behaviours in children and youth during the COVID-19 pandemic:Exploring the role of the neighborhood environment. Health Place 2020; 65: 102418. 